\title{
REALIZATION OF FUZZY LOGIC CONTROLLED BRUSHLESS DC MOTOR DRIVES USING MATLAB/SIMULINK
}

\author{
Mehmet Çunkaş ${ }^{1 *}$ Omer Aydoğdu ${ }^{2}$ \\ ${ }^{1}$ Department of Electronics and Computer, Technical Education Faculty, \\ Selcuk University,42003, Konya, Turkey. mcunkas@selcuk.edu.tr \\ ${ }^{2}$ Department of Electrical and Electronics Engineering, Faculty of Engineering and \\ Architecture, Selcuk University,42075, Konya, Turkey. oaydogdu@selcuk.edu.tr
}

\begin{abstract}
In this paper, an efficient simulation model for fuzzy logic controlled brushless direct current motor drives using Matlab/Simulink is presented. The brushless direct current (BLDC) motor is efficiently controlled by Fuzzy logic controller (FLC). The control algorithms, fuzzy logic and PID are compared. Also, the dynamic characteristics of the BLDC motor (i.e. speed and torque) and as well as currents and voltages of the inverter components are easily observed and analyzed by using the developed model
\end{abstract}

Key Words- BLDC Motor, Electric Drive Simulation, Fuzzy Logic, Matlab/Simulink

\section{INTRODUCTION}

BLDC motors have some advantages over conventional brushed DC motors and induction motors. Some of these are; better speed versus torque characteristics, high dynamic response, high efficiency, long operating life, noiseless operation and higher speed ranges. In addition, BLDC motors are reliable, easy to control, and inexpensive [1]. Due to their favorable electrical and mechanical properties, BLDC motors are widely used in servo applications such as automotive, aerospace, medical, instrumentation, actuation, robotics, machine tools, industrial automation equipment and so on recently [2-4].

Many machine design and control schemes have been developed to improve the performance of BLDC motor drives. The model of motor drives has to be known in order to implement an effective control in simulation. Some simulation models based on state-space equations, Fourier series, d-q axis model, and variable sampling have been proposed for the analysis of BLDC motor drives [5-10]. Furthermore, fuzzy logic controllers (FLCs) are used to analyze BLDC motor drives in literature [11-14].

The previous studies have made a great contribution to BLDC motor drives. But as far as we know, a comprehensive approach has not been available for modeling and analysis of fuzzy logic controlled brushless DC motor drives using MATLAB/Simulink. In this paper, a comprehensive simulation model with fuzzy logic controller is presented. MATLAB/fuzzy logic toolbox is used to design FLC, which is integrated into simulations with Simulink. The control algorithms, fuzzy logic and PID are compared. Several simulation results are shown to confirm the performance and the validity of the proposed model. The model based on system-level simulation makes the simulation faster while it is able to provide greater details of the BLDC motor drive system. Besides, considering that the computational time without affecting the accuracy of the results obtained is very low, it can be said that the proposed method is promising. 


\section{MODELLING AND SIMULATION OF BLDC MOTOR DRIVE SYSTEM}

The proposed control system, which contains two loops, is shown in Figure 1. The first loop is the current control loop that accomplishes torque control of BLDC motor and the second loop is the speed control loop that adjusts the speed of BLDC motor.

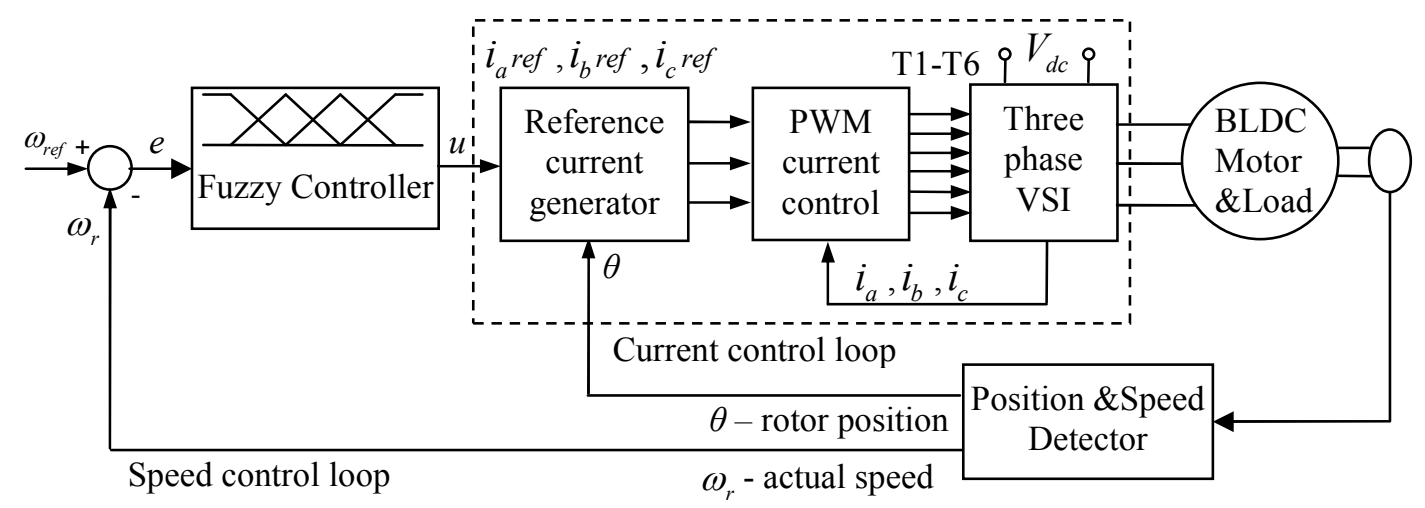

Figure 1. Fuzzy logic controlled BLDC motor drive system.

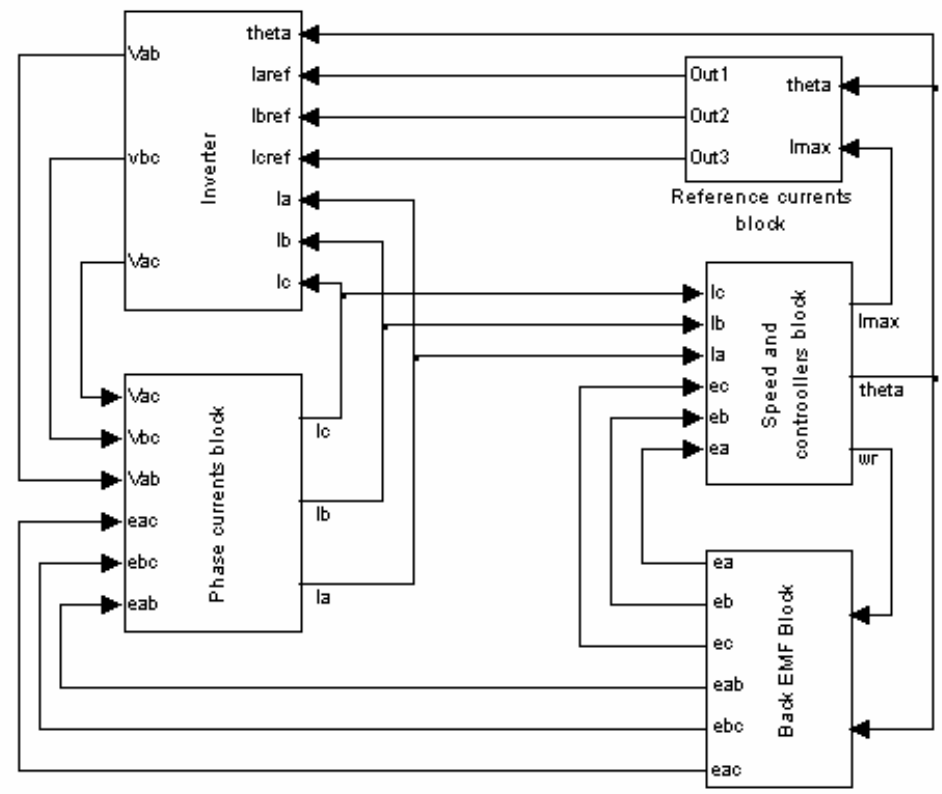

Figure 2. Simulink model of BLDC motor

Figure 2 shows the overall block diagram of the developed model for BLDC motor drives. The analysis of BLDC motor is based on the following assumptions for simplification and accuracy. BLDC motor is not saturated. Stator resistances are equal, self and mutual inductances are constant. Semiconductor devices of inverter are ideal. Iron losses are negligible. Back-EMF wave forms of all phases are equal. Based on the equivalent circuit of BLDC motor and VSI system shown in Figure 3, the dynamic equations of BLDC motors under the above assumptions are derived as:[2] 


$$
\left[\begin{array}{l}
v_{a} \\
v_{b} \\
v_{c}
\end{array}\right]=\left[\begin{array}{lll}
R & 0 & 0 \\
0 & R & 0 \\
0 & 0 & R
\end{array}\right]\left[\begin{array}{c}
i_{a} \\
i_{b} \\
i_{c}
\end{array}\right]+\left[\begin{array}{ccc}
(L-M) & 0 & 0 \\
0 & (L-M) & 0 \\
0 & 0 & (L-M)
\end{array}\right] \frac{d}{d t}\left[\begin{array}{c}
i_{a} \\
i_{b} \\
i_{c}
\end{array}\right]+\left[\begin{array}{c}
e_{a} \\
e_{b} \\
e_{c}
\end{array}\right]
$$

where; $v_{a}, v_{b}$, and $v_{c}$ are phase voltages, $R$ is resistance, $L$ is inductance, $M$ is mutual inductance, $e_{a}, e_{b}$, and $e_{c}$ are trapezoidal back EMFs. The motion equation is expressed as;

$\frac{d \omega_{m}}{d t}=\left(\frac{P}{2 J}\right)\left(T_{e}-T_{L}-B \omega_{r}\right)$ and $\frac{d \theta}{d t}=\omega_{r}$

where; $T_{e}$ is the electromagnetic torque, $T_{L}$ is the load torque in Nm, $J$ is the moment of inertia in $\mathrm{kgm}^{2}$, B is the frictional coefficient in $\mathrm{Nms} / \mathrm{rad}, \omega_{m}$ is rotor speed in mechanical $\mathrm{rad} / \mathrm{s}$. and $\omega_{r}$ is rotor speed in electrical $\mathrm{rad} / \mathrm{s}$.

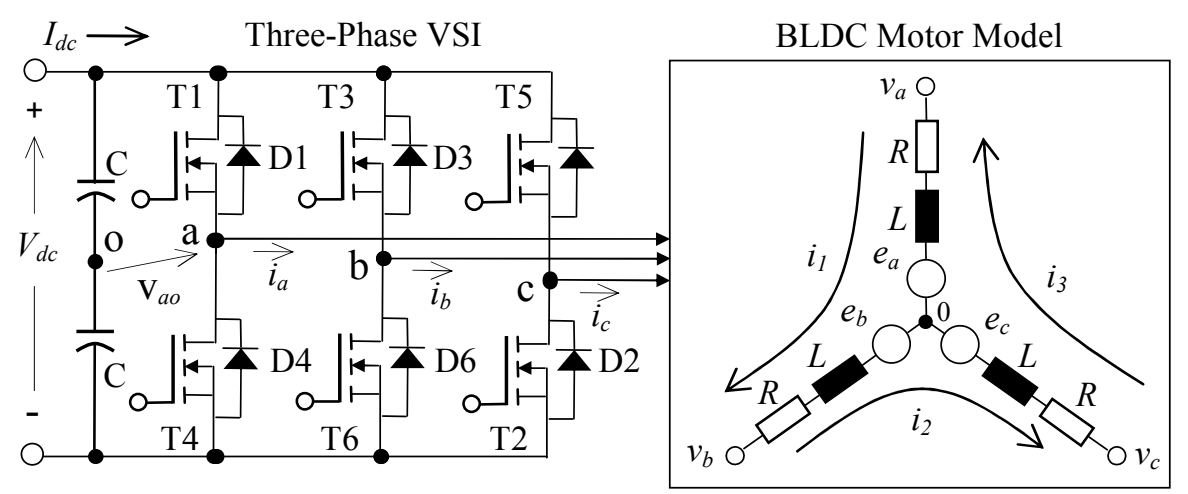

Figure 3. Configuration of BLDC motor and voltage source inverter (VSI) system

\subsection{Modeling of Trapezoidal Back EMF}

The trapezoidal back-EMF wave forms are modeled as a function of rotor position so that rotor position can be actively calculated according to the operation speed. The back EMFs are expressed as a function of rotor position $(\theta)$, which can be written as: [15]

$$
\left[\begin{array}{l}
e_{a} \\
e_{b} \\
e_{c}
\end{array}\right]=E\left[\begin{array}{l}
f_{a}(\theta) \\
f_{b}(\theta) \\
f_{c}(\theta)
\end{array}\right],\left(E=k_{e} \omega_{r}\right)
$$

where $k_{e}$ is back-EMF constant, $f_{a}(\theta), f_{b}(\theta)$, and $f_{c}(\theta)$ are the function of rotor position. The $f_{a}(\theta)$ named as trapezoidal shape functions with limit values between +1 and -1 is defined as:

$$
f_{a}(\theta)=\left[\begin{array}{ll}
(6 / \pi) \theta & (0<\theta \leq \pi / 6) \\
1 & (\pi / 6<\theta \leq 5 \pi / 6) \\
-(6 / \pi) \theta+6 & (5 \pi / 6<\theta \leq 7 \pi / 6) \\
-1 & (7 \pi / 6<\theta \leq 11 \pi / 6) \\
(6 / \pi) \theta-12 & (11 \pi / 6<\theta \leq 2 \pi)
\end{array}\right.
$$


$f_{b}(\theta)$ and $f_{c}(\theta)$ can be determined in a similar way. The electromagnetic torque is redefined using back-EMFs as follows:

$T_{e}=\left(T_{a}+T_{b}+T_{c}\right)=\left(e_{a} i_{a}+e_{b} i_{b}+e_{c} i_{c}\right) / \omega_{r}$

Substituting equations (3)-(4) into equation (5), the expression of the electromagnetic torque can be defined as:

$T_{e}=k_{e}\left(f_{a}(\theta) i_{a}+f_{b}(\theta) i_{b}+f_{c}(\theta) i_{c}\right)$

Based on the rotor position, the numerical expression of the back EMF can be obtained as Equation (3), and this is implemented as shown in Figure 4. Neglecting the damping factor, the speed and torque characteristics of BLDC motor can be stated as follows:

$$
\omega_{m}=\frac{P}{2 J} \int\left(T_{e}-T_{L}\right) d t=\frac{P}{2 J} \int\left[\left(T_{a}+T_{b}+T_{c}\right)-T_{L}\right] d t
$$

and thus the speed and torque control circuit can be implemented as shown in Figure 5.

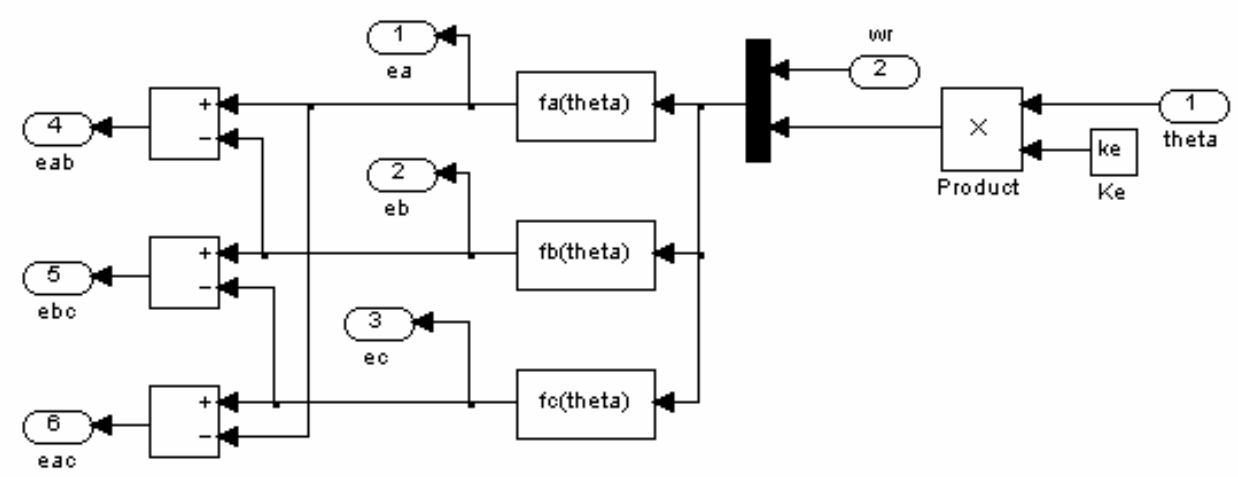

Figure 4. Simulink diagram for generating back EMF from rotor positions.

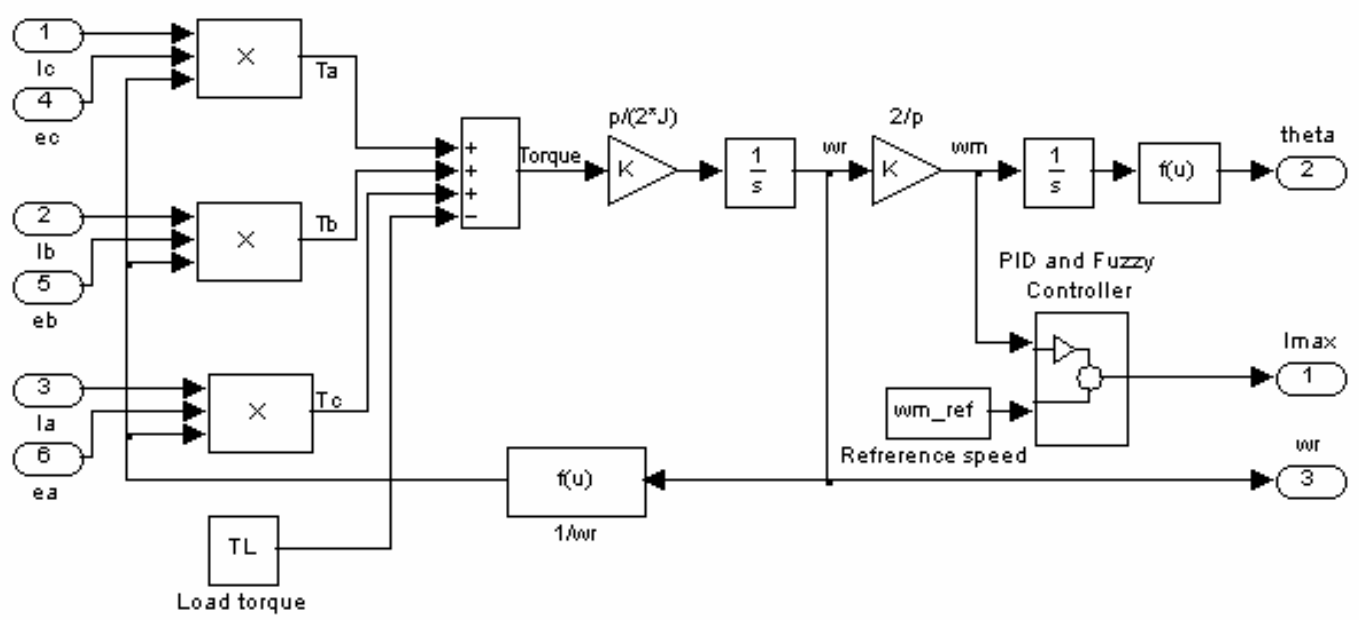

Figure 5. Simulink diagram for speed and torque control

\subsection{Voltage Source Inverter (VSI)}

As shown in Figure 3, only the two phases are excited through the conduction operating modes. Therefore, three-phase currents are considered in terms of the line-toline voltages. The following voltage and current equations can be obtained: [2] 


$$
\begin{aligned}
& v_{a b}=2 R i_{1}+2(L-M) \frac{d i_{1}}{d t}+e_{a b}, v_{b c}=2 R i_{2}+2(L-M) \frac{d i_{2}}{d t}+e_{b c}, \\
& \text { and } v_{c a}=2 R i_{3}+2(L-M) \frac{d i_{3}}{d t}+e_{c a}
\end{aligned}
$$

where $i_{1}, i_{2}$ and $i_{3}$ are the loop currents, $e_{a b}, e_{b c}$, and $e_{c a}$ are the line-to-line back EMFs: $e_{a b}=e_{a}-e_{b}, e_{b c}=e_{b}-e_{c}, e_{c a}=e_{c}-e_{a}$, and the phase currents: $i_{\mathrm{a}}=i_{1}-i_{3}, i_{b}=i_{2}-i_{1}$, $i_{c}=i_{3}-i_{2}$. Using the switching function $\mathrm{S}_{\mathrm{a}, \mathrm{a}, \mathrm{c}}$ which is obtained from hysteresis block, $v_{a o}, v_{b o}$, and $v_{c o}$ in reference to midpoint of DC supply voltage $\left(V_{d c}\right)$ can be calculated as;

$$
\begin{aligned}
& v_{a o}=\frac{V_{d}}{2} S_{-a}=\frac{V_{d}}{2} \sum_{0}^{\infty} A_{n} \sin (n \omega t), v_{b o}=\frac{V_{d}}{2} S_{-b}=\frac{V_{d}}{2} \sum_{0}^{\infty} A_{n} \sin [n(\omega t-120)], \text { and } \\
& v_{c o}=\frac{V_{d}}{2} S_{-c}=\frac{V_{d}}{2} \sum_{0}^{\infty} A_{n} \sin [n(\omega t-240)]
\end{aligned}
$$

Then the inverter line-to-line voltages can be derived as

$$
v_{a b}=v_{a o}-v_{b o}, v_{b c}=v_{b o}-v_{c o} \text {, and } v_{c a}=v_{c o}-v_{a o}
$$

The implementations of the above-explained numerical PWM inverter voltage and current equations [2] are shown in Figure 6 and 7.

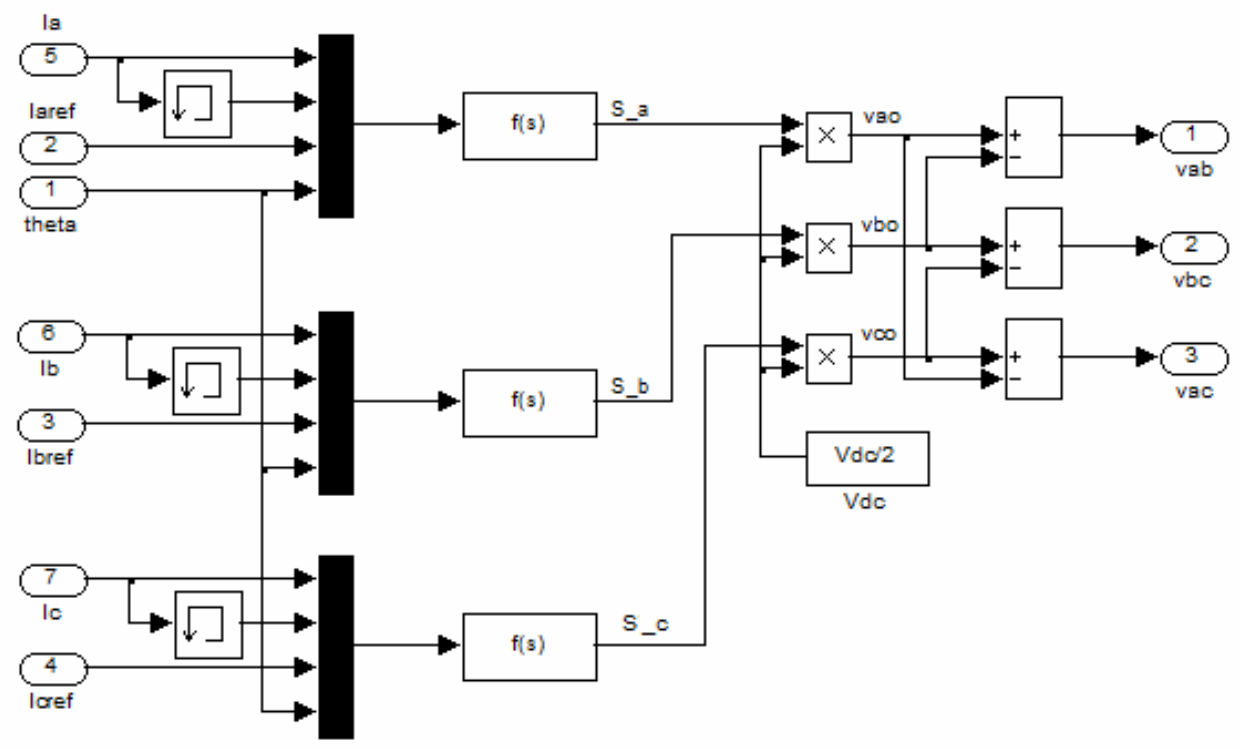

Figure 6. The generation of inverter line-to-line voltages

\subsection{Reference Current Generator}

The reference current generator determines motor's reference phase currents $\left(i_{a} r e f, i_{b} r e f, i_{c} r e f\right)$ by considering reference current amplitude (Imax), which is calculated depending on rotor position $(\theta)$. The reference current amplitude (Imax) can be obtained as

$$
\operatorname{Imax}=u / k_{t}
$$


where $(u)$ is the control signal obtained from fuzzy controller and $k_{t}$ is the torque constant of the BLDC motor. The reference phase currents given in Table 1 can be acquired from Figure 8.a. The function $\mathrm{f}(\mathrm{s})$ is defined according to Table 1. These currents are inputs to PWM current control block.

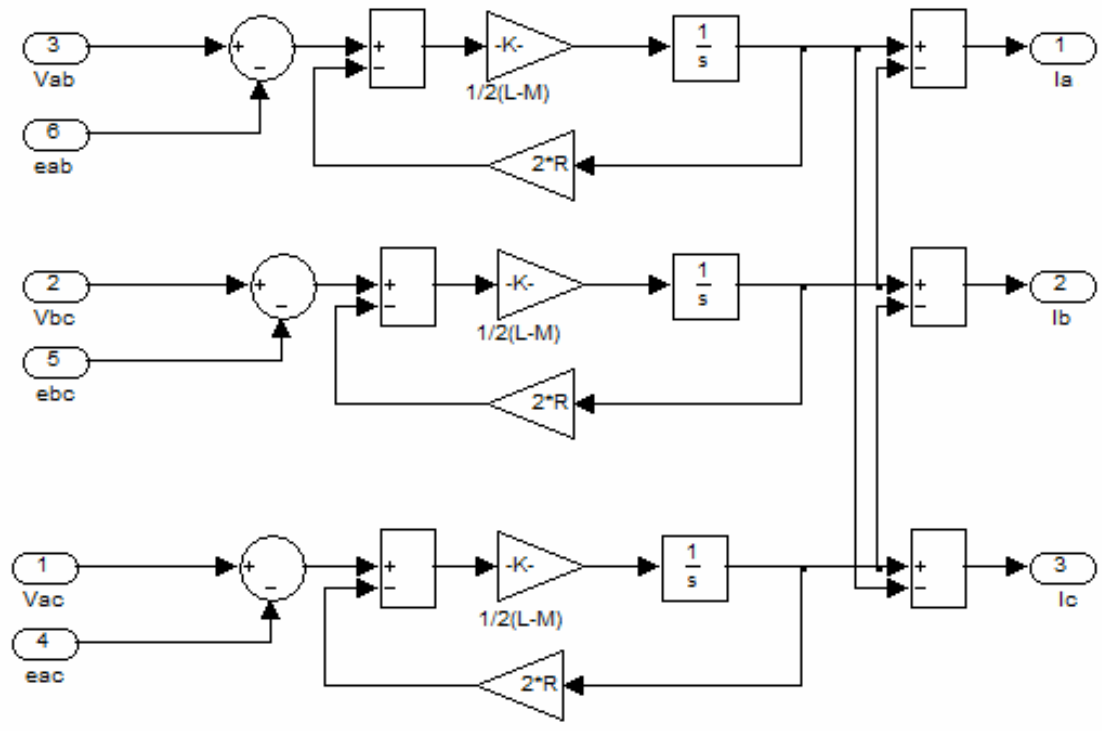

Figure 7. Simulink diagram for three-phase currents.

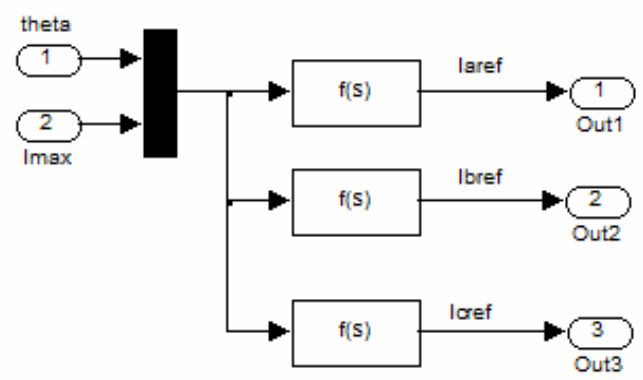

(a)

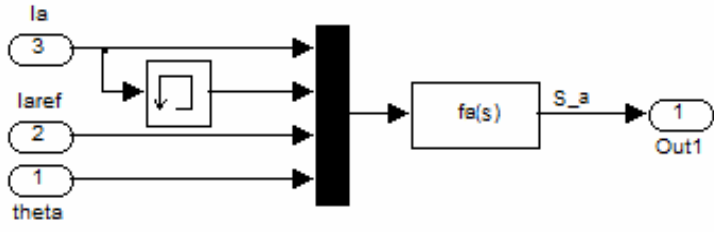

(b)

Figure 8. (a) Simulink diagram for reference currents (b) Implementation of hysteresis current control for phase A

\subsection{Current Control Block}

In PWM current control block, the reference phase currents $\left(i_{a} r e f, i_{b}\right.$ ref,$i_{c}$ ref $)$ are compared with the motor's actual phase currents $\left(i_{a}, i_{b}, i_{c}\right)$. The current errors are calculated as shown in Equation (13). These errors are applied to inverter hysteresis band $\left( \pm h_{b}\right)$ and the switching signals of three-phase PWM inverter system are generated according to the switching states. As shown in Figure 8.b, the hysteresis current control is performed in the function block fa(s) by using the measured phase current $i_{a}$, the reference current Imax, and the rotor position $\theta$, where the function block fa(s) is a term which consists of Equation (13) and (14). From the hysteresis block, the switching function S_a, S_b, and S_c are defined to model the operation of the PWM inverter [16]. 


$$
\begin{aligned}
& e_{i a}=i_{a} r e f-i_{a}, e_{i b}=i_{b} r e f-i_{b}, \text { and } e_{i c}=i_{c} r e f-i_{c} \\
& \text { if } e_{i a} \geq h_{b} \text { then } v_{a o}=V_{d c} / 2, \quad \text { if } e_{i a} \leq h_{b} \text { then } v_{a o}=-V_{d c} / 2 \\
& \text { if } e_{i b} \geq h_{b} \text { then } v_{b o}=V_{d c} / 2, \quad \text { if } e_{i b} \leq h_{b} \text { then } v_{b o}=-V_{d c} / 2 \\
& \text { if } e_{i c} \geq h_{b} \text { then } v_{c o}=V_{d c} / 2, \quad \text { if } e_{i c} \leq h_{b} \text { then } v_{c o}=-V_{d c} / 2
\end{aligned}
$$

\begin{tabular}{|c|c|c|c|}
\hline \multirow[t]{2}{*}{ Rotor position ( $\theta$-Degree) } & \multicolumn{3}{|c|}{ Reference currents (A) } \\
\hline & $i_{a} r e f$ & $i_{b}$ ref & $i_{c} r e f$ \\
\hline $0-30$ & 0 & -Imax & Imax \\
\hline $30-90$ & $\operatorname{Imax}$ & -Imax & 0 \\
\hline $90-150$ & $\operatorname{Imax}$ & 0 & $-\operatorname{Imax}$ \\
\hline $150-210$ & 0 & Imax & $-\operatorname{Imax}$ \\
\hline $210-270$ & -Imax & $\operatorname{Imax}$ & 0 \\
\hline $270-330$ & -Imax & 0 & $\operatorname{Imax}$ \\
\hline $330-360$ & 0 & -Imax & $\operatorname{Imax}$ \\
\hline
\end{tabular}

Table 1 Reference currents of BLDC motor

\subsection{Design of Fuzzy Logic Controller (FLC)}

The block diagram of FLC with two inputs $\left(e_{1}, e_{2}\right)$ and one output $(u)$ is shown in Figure 9. The error is calculated by subtracting the reference speed from the actual rotor speed as follows:

$e_{1}[n]=\omega_{r e f}[n]-\omega_{r}[n]$

where $e_{1}[n]$ is the error, $\omega_{r e f}[n]$ is the reference speed, and $\omega_{r}[n]$ is the actual motor speed. The change in error is calculated by Equation (16), where $e_{1}[n-1]$ is the previous error value.

$e_{2}[n]=e_{1}[n]-e_{1}[n-1]$

In the fuzzy logic control system, two normalization parameters $\left(N_{e 1}, N_{e 2}\right)$ for input and one denormalization parameter $\left(N_{u}\right)$ for output are defined. In normalization process, the input values are scaled between $(-1,+1)$ and in the denormalization process, the output values of fuzzy controller are converted to a value depending on the terminal control element.

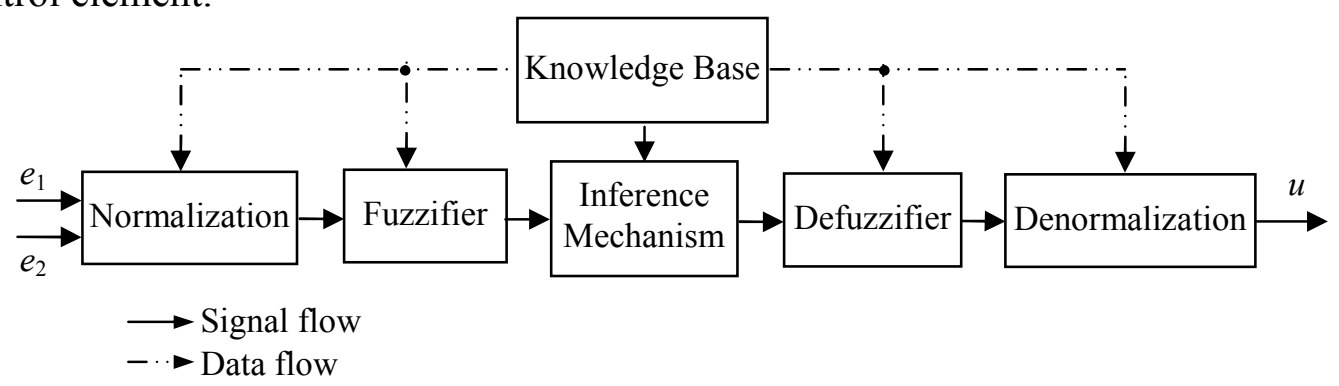

Figure 9. Structure of fuzzy logic controller

The fuzzy values obtained from fuzzy inference mechanism have to be converted to crisp output value $(u)$ by defuzzifier process. For this purpose, the triangle 
fuzzy membership function is defined for each input and output values by seven clusters. Figure 10 illustrates the membership function used to fuzzify two input values $\left(e_{1}, e_{2}\right)$ and defuziffy output $(u)$ of the fuzzy controller. For seven clusters in the membership functions, seven linguistic variables are defined as: Negative Big (NB), Negative Medium (NM), Negative Small (NS), Zero (Z), Positive Small (PS), Positive Medium (PM), and Positive Big (PB).

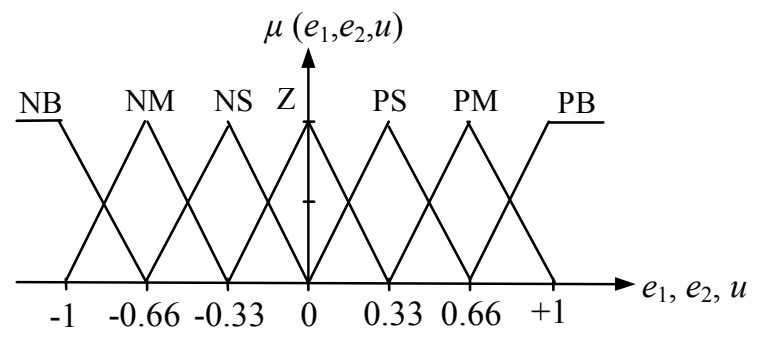

Figure 10. Membership functions of fuzzy controller

A sliding mode rule base used in FLC is given in Table 2. The fuzzy inference operation is implemented by using the 49 rules. The min-max compositional rule of inference and the center-of-gravity method have been used in defuzzifier process.

If $e_{1}$ is $\mathrm{NB}$ and $e_{2}$ is $\mathrm{NB}$ Then $u$ is $\mathrm{PB}$,

If $e_{1}$ is $\mathrm{NB}$ and $e_{2}$ is NM Then $u$ is $\mathrm{PB}$,

If $e_{1}$ is NB and $e_{2}$ is NS Then $u$ is PM,

If $e_{1}$ is $\mathrm{NB}$ and $e_{2}$ is $\mathrm{Z}$ Then $u$ is $\mathrm{PM}$,

and go on for all inputs.

MATLAB/Fuzzy Logic Toolbox is used to simulate FLC which can be integrated into simulations with Simulink. The FLC designed through the FIS editor is transferred to Matlab-Workspace by the command "Export to Workspace". Then, Simulink environment provides a direct access to the FLC through the MatlabWorkspace in BLDC motor drive simulation. Figure 11 shows the simulink diagram of Fuzzy logic and PID controllers. These control algorithms can be compared by using switch block. If the mid-point of switch block is '-1', FLC is selected, and in case the mid-point of switch block is ' 1 ', the PID is selected.

Table 2 Rule base of fuzzy controller

\begin{tabular}{|c|c|c|c|c|c|c|c|}
\hline \multirow[b]{2}{*}{ Input- $e_{1}$} & \multicolumn{7}{|c|}{ Input- $e_{2}$} \\
\hline & NB & NM & $\mathrm{NS}$ & $\mathrm{Z}$ & PS & PM & $\mathrm{PB}$ \\
\hline NB & $P B$ & $P B$ & $P M$ & $P M$ & $P S$ & $P S$ & $Z$ \\
\hline NM & $P B$ & $P M$ & $P M$ & $P S$ & $P S$ & $Z$ & $N S$ \\
\hline NS & $P M$ & $P M$ & $P S$ & $P S$ & $Z$ & $N S$ & $N S$ \\
\hline Z & $P M$ & $P S$ & $P S$ & $Z$ & $N S$ & $N S$ & $N M$ \\
\hline PS & $P S$ & $P S$ & $Z$ & $N S$ & $N S$ & $N M$ & $N M$ \\
\hline PM & $P S$ & $Z$ & $N S$ & $N S$ & $N M$ & $N M$ & $N B$ \\
\hline $\mathrm{PB}$ & $Z$ & $N S$ & $N S$ & $N M$ & $N M$ & $N B$ & $N B$ \\
\hline
\end{tabular}




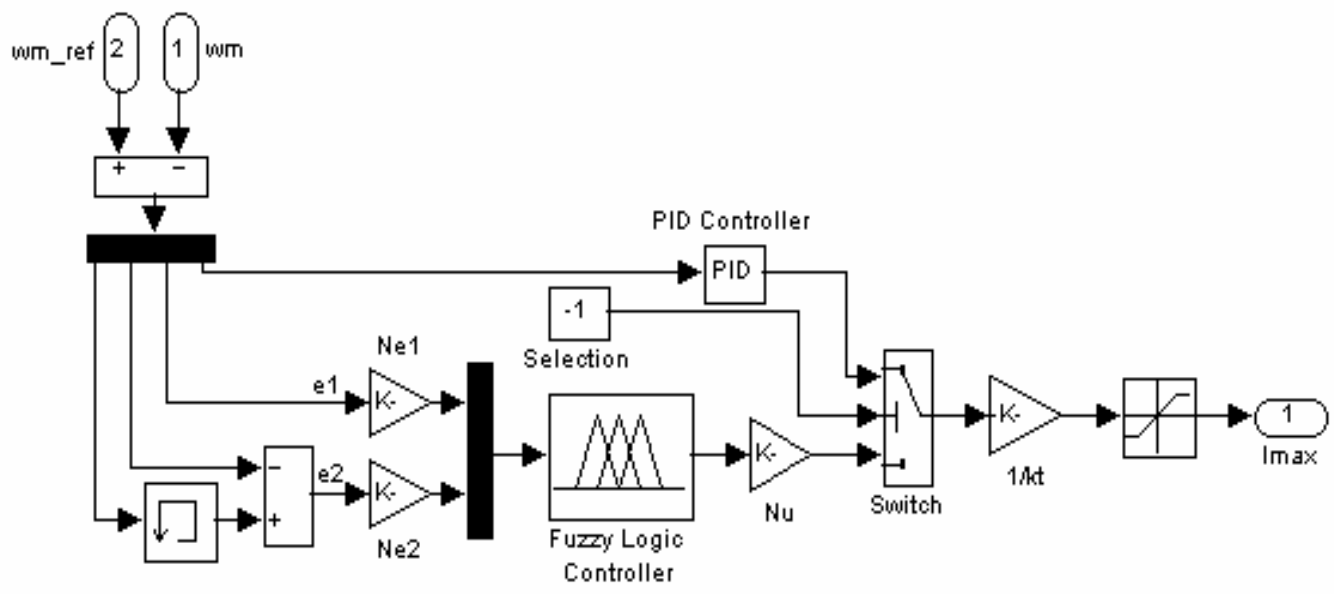

Figure 11. Simulink diagram of fuzzy logic and PID controllers

\section{SIMULATION RESULTS}

BLDC motor specifications used in simulation are shown in Table 3. The waveforms of generated back EMF according to the rotor position at $4050 \mathrm{rpm}$ are demonstrated in Figure 12.a. Three-phase symmetric back EMF waveforms are produced from the rotor position. The rotor position changes from 0 to $2 \pi$ per electric cycle $0.0148 \mathrm{~s}$ at $4050 \mathrm{rpm}$ and the amplitude of the back EMF is $17.78 \mathrm{~V}$. Figure 12.b shows the phase-current waveforms. The actual phase currents obtained by the hysteresis control algorithm are synchronized with their counterpart back EMF waveforms.
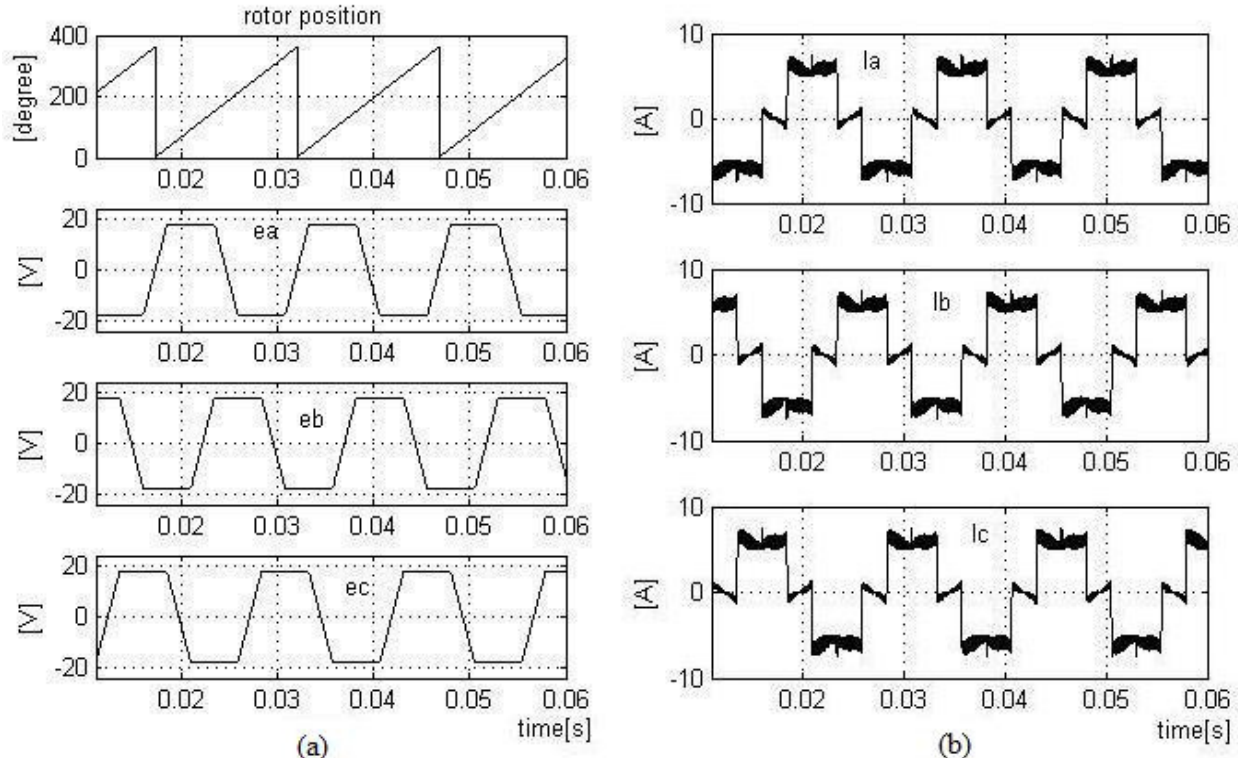

Figure 12. (a)Back EMF waveforms based on the rotor position at $4050 \mathrm{rpm}$. (b) Phase currents waveforms based on the rotor position at $4050 \mathrm{rpm}$.

Figure 13 shows the detailed operational characteristics of PWM inverter based on the switching function concept. The switching function for the phase A, S_a, is given 
in Figure 13. In order to hold the currents to be switched between the hysteresis upper and lower bands, the switching function signals are only produced during the 120 。 conduction periods. The positive and negative values represent the upper and lower switch or diode under the conducting state. The line-to-line voltage waveforms are obtained by using the switching function $\mathrm{S}$ _a. The produced line-to-line voltage $\left(v_{a b}\right)$ according to the conduction modes is demonstrated in Figure 14. Since T1 and T6 are simultaneously active as seen in Figure 3, the phase A and the phase B currents are positive and negative, respectively

Table 3 Parameters of BLDC motor

\begin{tabular}{ll}
\hline BLDC motor type & Ametek 119003-01 \\
Rating $(P)$ & $106 \mathrm{watt}$ \\
Number of Phase (Connection) & $3(\mathrm{Star})$ \\
Rated speed & $4228 \mathrm{rpm}$. \\
Rated current & $6.8 \mathrm{~A}$ \\
Stator equivalent resistance $(R)$ & $0.348 \Omega$ \\
Stator equivalent inductance $(L)$ & $0.314 \mathrm{mH}$ \\
Moment of inertia $(J)$ & $0.0019 \mathrm{Ncm}-\mathrm{s}^{2}$ \\
Number of Pole $(p)$ & 8 \\
Voltage constant $\left(k_{e}\right)$ & $0.0419 \mathrm{~V} / \mathrm{rad} / \mathrm{s}$ \\
Torque constant $\left(k_{t}\right)$ & $4.19 \mathrm{Ncm} / \mathrm{A}$ \\
\hline
\end{tabular}
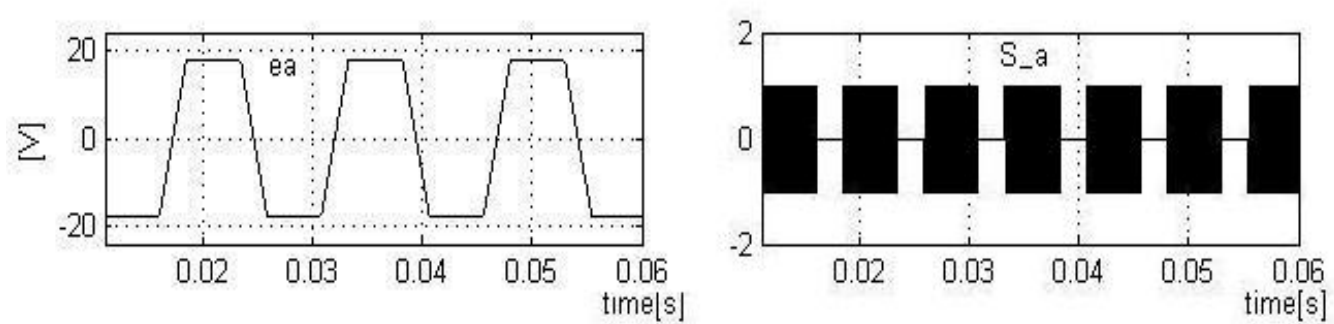

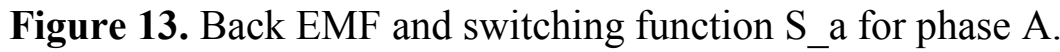
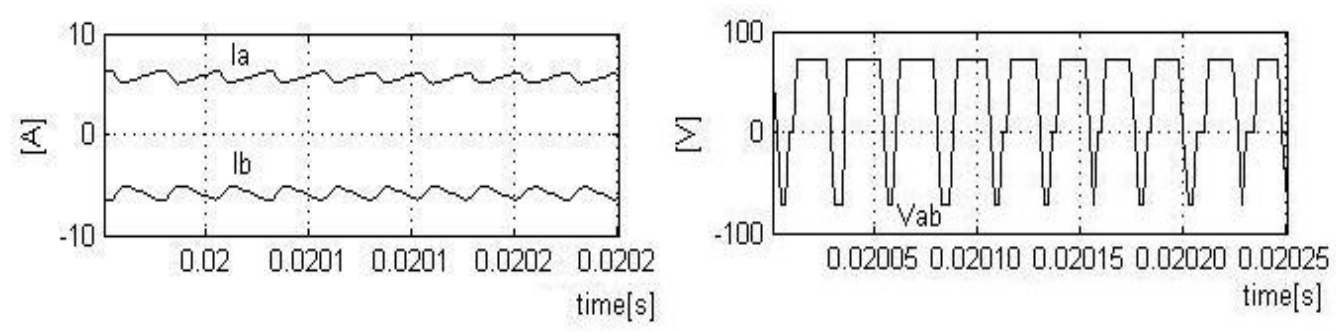

Figure 14. Phase currents and line to line inverter voltage

Figure 15 shows the dynamic responses of the speed, torque and Imax, respectively. The reference value of maximum current (Imax) is computed from the generated constant torque reference, consequently it is used in the hysteresis control block. Furthermore, the control algorithms, FLC and PID can be compared by using developed model. As shown in Figure 16 (a) and (b), if the PID controller is used, the real speed and torque reach the desired value in $6.5 \mathrm{~ms}$. On the other hand, if FLC is used, the real speed and torque reach the desired value in $5 \mathrm{~ms}$. In conclusion it can be said that unlike the classical controller, FLC is more effective in BLDC motor drives. 


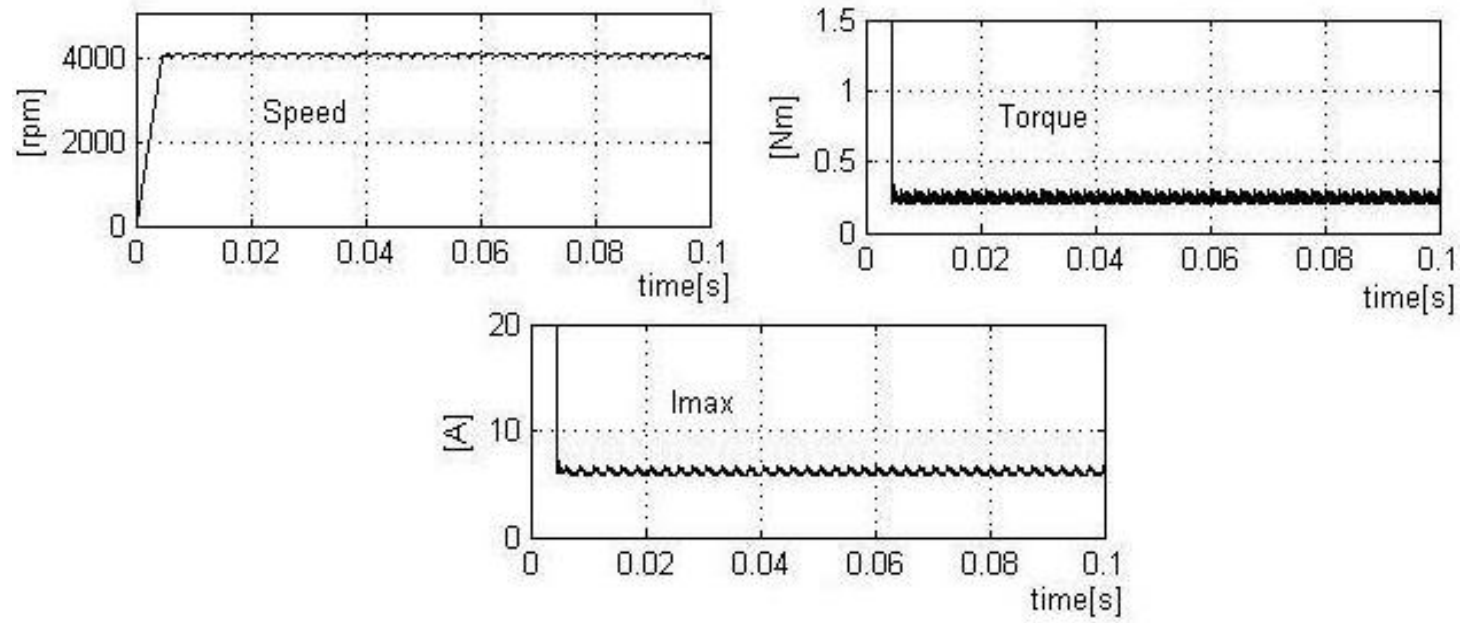

Figure 15 Electromagnetic torque, speed of BLDC motor, and maximum current (Imax)

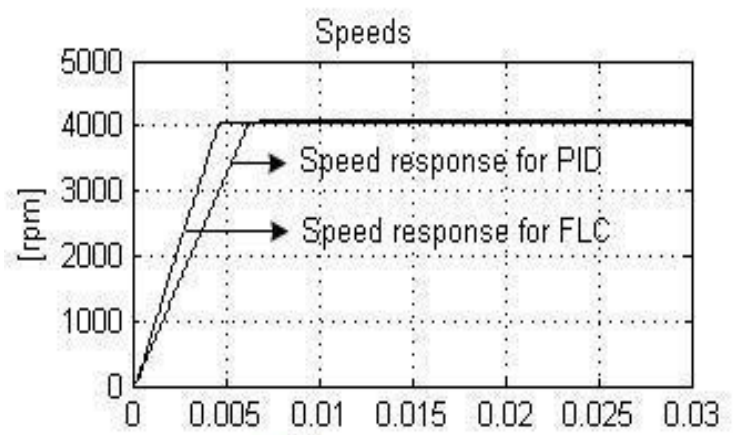

(a)

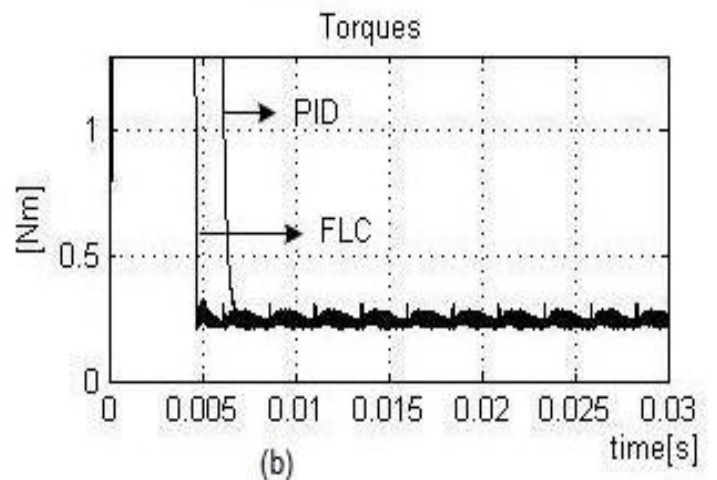

(b)

Figure 16. Comparison of PID and FLC (a) for speed (b) for torque

\section{CONCLUSIONS}

In this paper, a comprehensive analysis of brushless DC drive system has been performed by using fuzzy logic controller. The simulation model which is implemented in a modular manner under MATLAB/simulink environment allows that many dynamic characteristics such as phase currents, voltages, rotor speed, and mechanical torque can be effectively considered. Furthermore, the control algorithms, FLC and PID have been compared by using the developed model. It is seen that the desired real speed and torque values could be reached in a short time by FLC controller. The results show that MATLAB paired with simulink is a good simulation tool for modeling and analyze fuzzy logic controlled brushless DC motor drives.

\section{REFERENCES}

1. P. Yedamale, Brushless DC (BLDC) Motor Fundamentals. Chandler, AZ: Microchip Technology, Inc., last access; March 15, 2009. [Online].Available: http://ww1.microchip.com/downloads/en/Market_Communication/Feb\%202009\%20mi croSOLUTIONS.pdf

2. B.K. Lee and M. Ehsani, Advanced Simulation Model for Brushless DC Motor Drives, Electric Power Components and Systems 31, 841-868, 2003. 
3. W. Hong, W. Lee, and B.K. Lee, Dynamic Simulation of Brushless DC Motor Drives Considering Phase Commutation for Automotive Applications, Electric Machines \& Drives Conference, IEMDC '07, 2007.

4. R. Akkaya, A.A. Kulaksız, and O Aydogdu, DSP implementation of a PV system with GA-MLP-NN based MPPT controller supplying BLDC motor drive, Energy Conv. and Management 48, 210-218, 2007.

5. P. Pillay and R. Krishnan, Modeling, simulation, and analysis of permanent-magnet motor drives, part II: the brushless DC motor drive, IEEE Trans. on Industry Applications 25, 274-279, 1989.

6. P.D. Evans and D. Brown, Simulation of brushless DC drives, Proc. of the IEE 137, 299-308, 1990.

7. R. Carlson, M. Lajoie-Mazenc, and C.D.S. Fagundes, Analysis of torque ripple due to phase commutation in brushless DC machines, IEEE Trans. on Industry Applications 28, 632-638, 1992.

8. S.K. Safi, P.P. Acarnley, and A.G. Jack, Analysis and simulation of the high-speed torque performance of brushless DC motor drives, Proc. of the IEE 142, 191-200, 1995.

9. J. Figueroa, C. Brocart, J. Cros, and P. Viarouge, Simplified simulation methods for polyphase brushless DC motors, Mathematics and Computers in Simulation 63, 209-224, 2003.

10. C.W. Hung; C.T. Lin, and C.W. Liu, An Efficient Simulation Technique for the Variable Sampling Effect of BLDC Motor Applications, IECON 2007, pp. 11751179, 2007.

11. CK. Lee and WH. Pang, A Brushless DC Motor Speed Control System Using Fuzzy Rules, IEE Power Electronics and Variable Speed Drives, pp.101-106, 1994.

12. R.N. Tuncay, Z. Erenay, M. Y1lmaz, and Ö. Üstün, Rapid Control Prototyping Approach to Fuzzy Speed Control of Brushless DC Motor, ELECO'03, International Conference on Electrical and Electronics Engineering, Bursa, Turkey, 2003.

13. C. Xia, P. Guo, T. Shi, and M. Wang, Speed control of brushless de motor using genetic algorithm based fuzzy controller, Proc. of Int. Conf. on Intelligent Mechatronics and Automation, pp.460-464, 2006.

14. A. Rubai, A. Ofoli, and M. Castro, dSPACE DSP-Based Rapid Prototyping of Fuzzy PID Controls for High Performance Brushless Servo Drives, IEEE Industry Applications Conference, 41st IAS Annual Meeting, page(s):1360-1364, 2006.

15. B. Sing, A.H.N. Reddy, and S.S. Murthy, Gain Scheduling Control of Permanent Magnet Brushless dc Motor, IE(I) Journal-EL 84, 52-62, 2003.

16. B.K. Lee and M.A. Ehsani, Simplified functional model for 3-phase voltage-source inverter using switching function concept, IEEE Trans. on Industrial Electronics 48, 309-321, 2001. 